\title{
Influence of Health Education on Prevention of Drug Abuse
}

\section{${ }^{* 1}$ CHUKWUKA, LUCY OMONON ${ }^{2}$ AGOREYO FREDDY}

\author{
Department of Nursing, School of Basic Medical Sciences, College of Medical Sciences, University of Benin \\ Department of Physiology, School of Basic Medical Sciences, College of Medical Sciences, University of Benin \\ Email Address: agoreyofo@yahoo.com
}

\begin{abstract}
The increasing scourge of drug abuse among adolescents is a major challenge facing mankind. As the importance of health education in disease prevention is enormous, drug misuse prevention programme requires introducing innovations, flexibility and reinforcement which will be effective in shortest possible time among the greatest number of people. This study was undertaken to investigate the influence of health education on prevention of drug abuse. 192 adolescents comprising of male and females, randomly selected from two secondary schools and a university were used as sample with ages ranging from 1222 years with a mean of 17years. The questionnaire, "DA Behaviour Inventory" was administered on the sample. Data was collected and analyzed using the t-test statistics at 0.05 level of significant difference. The findings showed that there is no significant difference in the pattern of drug abuse between adolescents with knowledge of drug education and those without knowledge of drug education. There is no significant difference in the pattern of drug abuse between male and female adolescents, there is no significant difference between the pattern of drug abuse of adolescents from upper and lower socio-economic background. Also there is no significant difference in the pattern of drug abuse of early and late adolescents. These findings were discussed and the implications as well. Recommendations and suggestions for further research were given. CJASEM

http://dx.doi.org/10.4314/jasem.v19i2.16
\end{abstract}

\section{KEYWORD Adolescents, Alcohol, Drug abuse, Education, Pattern}

\section{INTRODUCTION}

Substance abuse has become one of the most widespread and serious public health problems in this century. Involving an increasingly broad spectrum of drugs and alcohol, the epidemic of substance abuse is affecting countries everywhere, both developed and developing. As both a health and social problem in its own right, and also as a major underlying factor in a range of other physical and psychosocial health problems, substance abuse is currently influencing more people and adolescents especially than ever before.

The abuse of drugs and alcohol constitutes one of the main causes of impairment of social competence and performance in the case of otherwise healthy young people for instance; behavioural problems associated with substance abuse are currently among the most important reasons for interrupted social and intellectual development. Tobler (1992) remarked that most adolescents are at risk for drug use and misuse and few if any are invulnerable. They have friends and acquaintances that use drugs and therefore experience pressure from then to conform to the norms of the group. Substance use starts in adolescence and follows a progression that typically begins with the use of gateway substances (cigarettes, alcohol and marijuana) and progress later to the use of harder substances. Emotional factors such as low self esteem, low sense of control, low self confidence, increased anxiety and impulsivity and lower assertiveness have been shown to increase risk for substance abuse. In terms of social factors one of the earliest influences is the family, which may provide behavioral models for substance use. The adolescence connection to the community is also important. Research shows that the bond between the adolescent and society and the adolescent's belief in the society are inversely correlated with substance use while alienation from societal values is positively associated with substance use.

The curative, rehabilitative and legal modalities earlier employed to combat drug and substance abuse have not yielded appreciable result, many individuals and groups are now resorting to preventive measures which are better, cheaper and healthier. The best strategy for implementing and attaining this goal is through Health education. Through health education, people can be helped to understand their behavior and how it affects their health. People are encouraged to make their own choices for a healthy life. 
Objective: This objective of this study was to investigate the influence of health education on prevention of drug abuse among adolescents.

\section{MATERIALS AND METHOD}

In this study the descriptive survey method is used as the research approach. The variables studied were knowledge of drug education, sex, socio-economic status and age range. The socio economic status was determined by the level of parental education and occupation. Information concerning the variables were supplied in the questionnaire administered to the subjects.

Subjects: The subjects (both male and females) were adolescents randomly selected from two secondary schools, St. Louis Grammar School, Ibadan and St. Kizito's High School, Iwopin, Ogun waterside and the University of Ibadan. The subjects were divided between early (12-15years) and late adolescent (1622years).

Instrument and Procedure: The research instrument used for this study was a structured questionnaire titled "D.A. Behaviour Inventory (DABI)". It was meant to tap the social, familial and personal factors affecting drug use among Nigeria adolescents. The questionnaire starts with the objective for which the questionnaire was designed. Followed by personal data column where the respondent will supply identification information such as sex, age, class or educational level, religion, parents' occupation and educational background. Next is the main body of the questionnaire which is to test their drug perspectives and drug relief system. It was according to substance abuse namely, Alcohol, analgesics, Stimulants, Depressants and Caffeine. The questionnaire were in five likert scale namely "Strongly Agree (SA)" 5 points, "Agree (A)" 4 points, "Not sure (NS)" 3 points, "Disagree (D)" 2 points, Strongly Disagree (SD)" 1 point.

The questionnaires were administered to secondary school adolescents collectively in their classrooms. The aims and objectives of the study were highlighted and the confidentiality of the information supplied was guaranteed. The subjects were instructed on how to rate themselves. The same was done for those in the University of Ibadan.

Statistical Analysis: The t-test statistics was used to analyze the data. Each of the hypothesis was tested at the 0.05 level of significance.

\section{RESULTS AND DISCUSSION}

Table 1: means, standard deviations and t-test based on adolescents with knowledge of drug education and those without knowledge of drug education scores on means of drug abuse.

\begin{tabular}{lcccccccc}
\hline Variable & No & X & SD & df & t-Obs & t-Crit & P & \\
\hline Drug Education & 54 & 56.76 & 11.71 & 106 & 0.36 & 1.98 & 0.05 & NS \\
No Drug Education. & 54 & 63 & 11.65 & & & & & \\
\hline
\end{tabular}

The above table shows that there is no significant difference in the pattern of drug abuse of adolescents with knowledge of drug education and these without knowledge of drug education.

Table 2: means, standard deviations and t-test based on male and female students'

\begin{tabular}{lccccccc}
\multicolumn{7}{c}{ scores on measures of drug use. } \\
\hline Variable & No & $\mathbf{x}$ & SD & df & t-Obs & t-Crit & p \\
\hline Male Adolescents & 91 & 61.47 & 17.07 & 189 & 0.42 & 1.96 & NS \\
Female Adolescents & 100 & 58.82 & 14.76 & & & & \\
\hline The above table shows that there is no significant difference in the pattern of \\
drug use among male and female adolescents.
\end{tabular}

Table 3: means and standard deviations and t-test based on high and low socio-economic class adolescents score on measures of drug use.

\begin{tabular}{lccccccc}
\hline Variable & No & X & SD & df & t-Obs & t-Crit & p \\
\hline Upper class home Adolescents & 112 & 60.6 & 16.63 & 191 & 0.20 & 1.96 & NS \\
Lower class home Adolescents & 81 & 60.28 & 14.96 & & & & \\
\hline
\end{tabular}

The above shows that there is no significant difference in the pattern of

drug abuse of students from upper socio-economic and lower socio-economic class homes.

Table 4: means, standard deviations and t-test based on early and late adolescence 


\begin{tabular}{lccccccc}
\multicolumn{7}{c}{ scores on measures of drug use. } \\
\hline Variable & No & \multicolumn{1}{c}{ X } & SD & df & t-Obs & t-Crit & p \\
\hline Early Adolescents & 23 & 62.96 & 16.68 & 190 & 1.09 & 1.96 & NS \\
Late Adolescents & 169 & 59 & 16.2 & & & & \\
\hline
\end{tabular}

The above table revealed that there is no significant difference in the pattern of drug abuse of students in early and late adolescence.

The finding in the first group(table 1) shows that completing well designed prevention programmes for adolescents on drugs and alcohol including their use, side effects and social and physiological implications, only increased their information level as well as alcohol use.

The result conform to the report of Goodstadt (1989)) in which no significant changes were observed in the subject's attitude to alcohol and drug use after using a multicomponent drug prevention education strategy. The finding is also in line with the findings of Robert et al., (1995) who indicated that the effects of educational programmes in prevention by the Police was not significant and that what has emerged is the apparent failure of such programmes to substantially influence patterns of use. The findings is also in line with the report of Dusenbury and Botvin (1992) that some studies actually increased experimentation, possibly because they stimulated curiosity about drugs, and that the prevention programmes replicate the unsuccessful "scare tactics" and continue to be ineffective in reducing adolescent drug use.

The finding in the second group (table 2) shows that there will be no significant difference in the pattern of drug abuse in male and female adolescents. This finding supports the discovery of Elegbede (1995) that the attitude towards drinking and need for achievement is a common feature of adolescents in the Nigeria cultural environment. The trait as revealed in the study is uncluttered by gender influence. She stressed that whether male or female Nigerian adolescents still betray a less than positive attitude towards the habit of drinking.

The third finding was that there will be no significant difference in the pattern of drug abuse of adolescents from upper and lower socio-economic class homes as seen in table 3 . One possible reason for this result is that irrespective of the class adolescents belongs, they get influenced through peer group's interaction. They have friends who use drugs and therefore experience pressure from them to conform to the norms of the group and as part of maturation adolescents are beginning to rely less on their parents and more on their peers from validation and direction (Tobler, 1992; Dusenbury and Botvin, 1992).
The fourth finding shows that there is no significant difference in the pattern of drug abuse of early and late adolescence as seen in table 4. This result has to do with assertion of Tobler (1992) that adolescence is often characterized by a sense of immorality and invulnerability to danger which may result in underestimation of risks of substance abuse.

Conclusion: This study has been able to show that Education on drugs in adolescents have little or no effects on drug abuse especially when they are already Adolescents. There is also no significant difference in the pattern of drug abuse in early and late adolescence.

\section{REFERENCES}

Drug Abuse Update (1992) Special drug abuse pullout section, No 42, P. 19 published by national families in action Atlanta Georgia.

Dusenbury, L and Botvin, G.I. (1992) Substance abuse prevention: competent enhancement and the development of positive life options. Journal of addictive disease. Vol. 11 (3): 29-43.

Elegbeleye, S.O. (1995). Drinking habits and need for achievement in Nigeria adolescents. Nigerian Journal of Clinical and Counseling Psychology. Vol. 1:56-66

Goodstadt S M (1989) Substance abuse curricula vs. school drug policies. Journal of School Health; 59(6):24650 .

Ohaeri, J. (1995). Description of and method for teaching Nigerian children about drug abuse. Nigerian Journal of clinical and counseling psychology. Vol. 2:56-66

Robert T. Sigler, Gregory B. Talley (1995): Drug abuse resistance education program effectiveness. American Journal of Police; 14(3/4):111-121.

Tobler, N.S. (1992). Drug prevention programmes can work: research findings. Journal of Addictive Diseases. Vol. 2:1-8

WHO (1988) Education for health. A manual for health education in primary health care, WHO Geneva, printed in England.

World Health Forum (1997).Coping with substance abuse. International journal of health development. Vol. 13:105 